\title{
The bioclimatic approach in developing smart urban isles for sustainable cities
}

\author{
Despina Kyprianou Serghides* , Stella Dimitriou, Ioanna Kyprianou, and Costas Papanicolas \\ Energy, Environment, Water Research Centre, The Cyprus Institute, 20 Konstantinou Kavafi, 2121 Nicosia, Cyprus
}

Accepted: 6 December 2018

\begin{abstract}
The rapid trends of urbanization have catastrophic consequences on the ecology of our cities. The large amounts of energy consumption and the reckless exploitation of natural resources is leading to increased emissions of ozone depleting gases and carbon dioxide emissions, which are polluting our planet and enhancing the effects of global warming. This paper will present the bioclimatic approach in achieving a smart urban isle as a basic unit for the development of sustainable cities of the EU ERANET project "Smart bioclimatic low-carbon urban areas as innovative energy isles in the sustainable city" (SUI). It will outline the project and demonstrate the approach of achieving bioclimatic urban isles through the Cyprus case study. The main aim of the SUI project is to develop sustainable cities through balancing locally the energy systems. Thus, the project aspires to move forward with the urban energy and $\mathrm{CO}_{2}$ reduction. The study will focus on the bioclimatic approach, which is one of the three cornerstone procedures (Bioclimatic design, Smart Grids and Management Platform) on which the project is based. It will exemplify how the various aspects of the bioclimatic design and the utilization of the beneficial aspects of the surrounding environment are exploited and applied on defined urban isles, as a basic unit of the city.
\end{abstract}

\section{Introduction}

The intense urbanisation observed from 1950 (30\% urban dwellers) to today ( $55 \%$ urban dwellers), in conjunction with increasingly energy-intensive lifestyles, has led to voracious patterns of global energy consumption, especially in heavily urbanised areas [1-3]. Indicatively, cities are estimated to consume $75 \%$ of the natural resources and emit between 60 and $80 \%$ of the global greenhouse gas (GHG) emissions, while occupying 3\% of the Earth's land surface [4]. These patterns indicate not only a steep increase in the urban population globally but also drainage of natural resources and simultaneous increase of pollution caused by urban centres.

The approach of bioclimatic architecture is well established. The bioclimatic design considers the building from the stage of its inception as a place of energy exchange between the indoor and the external environment, natural and climatic; as a dynamic structure which utilises the beneficial climatic parameters (solar radiation for winter, sea breezes for summer, etc.), whilst avoiding the adverse climatic effects; cold winds for winter, solar radiation for summer [5]. Bioclimatic buildings aim to address three

\footnotetext{
* e-mail: d.serghides@cyi.ac.cy
}

main challenges encountered in urban centres: energy conservation, health and well-being of inhabitants and sustainability [6]. In addition to the structural design of the building, determining is the human factor. It was shown that the ability of users to manually operate elements of the building (e.g. windows) improves thermal comfort and energy conservation [7]. The bioclimatic design and functionality of buildings can and should be extended to the urban area surrounding them. The need for such approaches is critical in urban settings, due to the Urban Heat Island effect (UHI). UHI is a phenomenon characterised by increased urban temperatures relative to the surrounding rural and suburban spaces. Some of the impacts of the UHI effect include high energy consumption for cooling, low thermal comfort levels and increased mortality and morbidity rates [8].

The bioclimatic approach has the capacity to improve indoor and outdoor thermal conditions. Components of bioclimatic design with regard to outdoor open spaces include urban canopy and geometry, surface materials utilised as well as vegetation and water surfaces of the locale $[9,10]$. Of course, bioclimatic design of outdoor areas has an impact on the energy needs of adjacent buildings. For example, a case study performed in low-income dwellings in Cyprus showed that the orientation of buildings affects indoor temperatures, illustrating that 

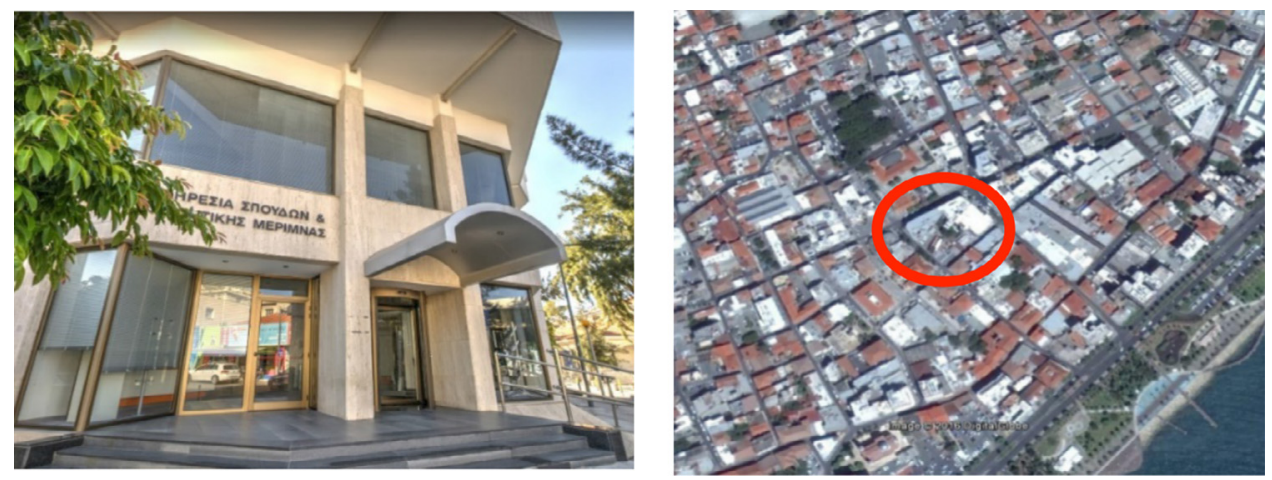

Fig. 1. Public building (left); 2. Limassol urban Isle area (inside red circle) (right).

urban geometry can influence the building's energy consumption and indoor thermal comfort [11]. The existing literature on bioclimatic design primarily considers case studies of certain regional characteristics, with the results being applicable mainly to areas with similar attributes. For example, in a refurbishment study it was estimated that adding movable shading devices to an existing single family house of the Mediterranean region was the optimal solution for energy conservation and economic viability [12]. A similar study in a Cyprus dwelling also suggested external bioclimatic interventions (horizontal overhangs) within a range of measures that could be applied to refurbish an existing dwelling into a nearly zero energy building (nZEB), with a payback period of less than 1 year [13].

The present study will explore bioclimatic applications on an existing urban isle located in the coastal city of Limassol, in Cyprus. The urban isle is defined as an area around public building(s), which makes use of synergies amongst different building functions and scale advantages for energy solutions. The case study for this urban isle is part of the project "Smart bioclimatic low-carbon urban areas as innovative energy isles in the sustainable city" (SUI). This project adopts a threefold approach: Smart Grids (decentralized renewable energy generation, energy storage and distribution), Management Platform (manage and provide optimal energy flow) and Bioclimatic methodology in building design and urban planning [14]. Essentially, bioclimatic units of the urban fabric (urban isles) are examined in relation to their inter-connectability and management through an intelligent platform.

\section{Description of case study}

The aim of this investigation was to determine the human comfort conditions in the case study of a (public) building and area and calculate their energy efficiency. This section describes the case study building and area as well as the key performance indicators related to energy consumption and emissions in the area.

\subsection{The SUI public building}

The public building under study is a four-floor (ground floor, mezzanine, first and second floor) University
Table 1. Limassol building envelope thermal transmittance values.

\begin{tabular}{ll}
\hline Envelope element & U-value $(\mathrm{W} / \mathrm{m} 2 \mathrm{~K})$ \\
\hline Main concrete wall & 3.33 \\
Secondary brick & 1.18 \\
Roof & 1.36 \\
Floor & 0.87 \\
Windows - double glazed & 2.00 \\
Windows - single glazed & 6.00 \\
\hline
\end{tabular}

Administration building constructed in 1979 and renovated in 2010 (Fig. 1, left). It is equipped with various services, including approximately 60 workplaces, a lecture room for 30 people and 2 meeting rooms. It is located in the old town neighbourhood of Limassol, near the seafront, a commercial area with up to seven-storey buildings surrounding it. Although recently refurbished, the building is not insulated. Details on the thermal performance of the envelope elements can be found in Table 1.

The case study building's loadbearing structure is reinforced concrete. The main wall structure is reinforced concrete with brickwork, cladded partially outside with travertine marble, whereas the main roof structure is reinforced concrete, polystyrene, cement screed and waterproof membrane. The floor is comprised of reinforced concrete, screed concrete, raised floor with final layer of parquet in the ground floor or fitted carpet. For the simulation with Design Builder, the heating and cooling temperatures were set at 22 and $26^{\circ} \mathrm{C}$, respectively, based on the onsite observation and the thermal comfort survey.

The building was modelled with both Design Builder and iSBEM software. The latter is the official tool for the energy certification of buildings in Cyprus. The results indicate that the simulation generated by Design Builder gives smaller deviation from the real consumption than the one generated by iSBEM (Fig. 2), since Design Builder is a dynamic simulation program.

The breakdown of energy consumption per energy service for the case study is illustrated in Figure 3, as simulated with Design Builder. Currently, the most energy-consuming service is cooling, followed closely by 


\section{Current energy performance}

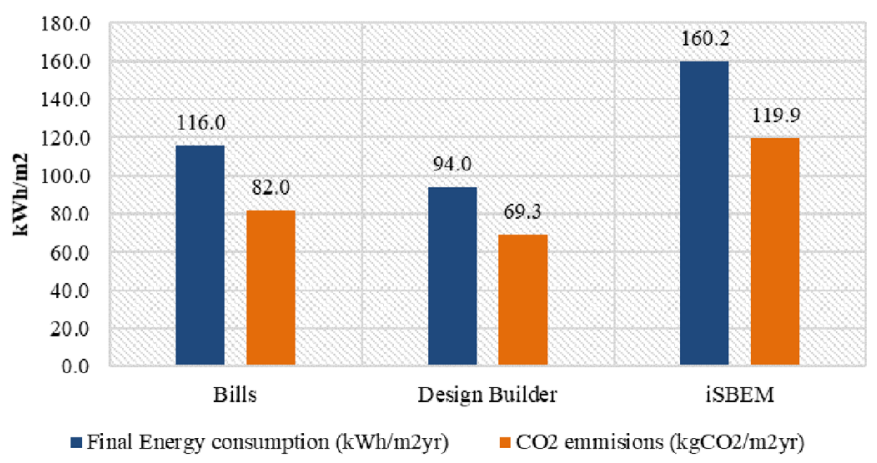

Fig. 2. Limassol building current energy performance.
Energy consumption per energy need (Design Builder)

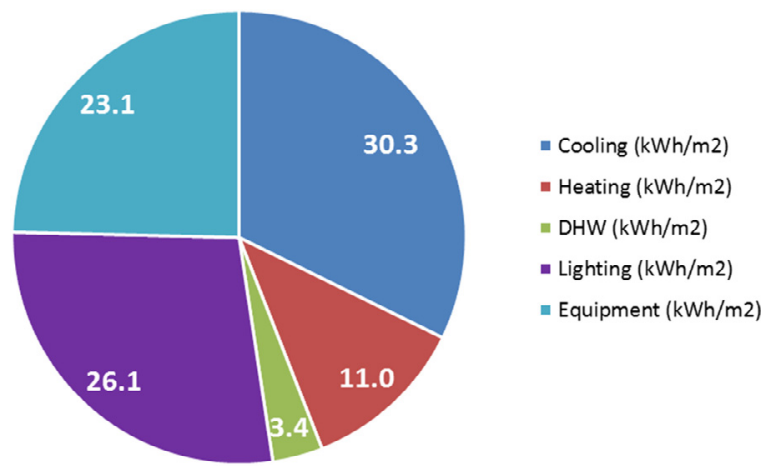

Fig. 3. Limassol building energy consumption breakdown (Design Builder).

Table 2. Energy profiles of the isle buildings.

\begin{tabular}{lll}
\hline Emissions & Number of properties & 20 \\
& $\mathrm{CO}_{2}$ emissions (ton/year) & 451.6 \\
& Average $\mathrm{CO}_{2}$ emissions per building (kg/year) & 22,942 \\
\hline Electricity & Total electricity consumption (MWh/year) & 710.9 \\
& Average electricity consumption per building (KWh/year) & 35,544 \\
\hline
\end{tabular}

lighting and equipment. Heating is only responsible for about $12 \%$ of the total consumption of the building, suggesting that the proposed measures should focus on the more draining energy services of the building.

\subsection{The SUI area buildings}

The urban isle is located in the built-up area of the town of Limassol, adjacent to the main commercial street (Anexartisias street) and the headquarters of the Cyprus University of Technology (Fig. 1, right). There are various open spaces nearby, such as squares and parking lots. There are old stone buildings of one and two storeys and newer concrete structures of more than three floors. The area is occupied by retail stores, university buildings, cafeterias and bars.

Real consumption data from a report provided by the Ministry of Commerce, Industry and Tourism [15] were used to determine the energy profile of the 20 non-public buildings of the Isle (Tab. 2). From this information, the energy consumption per energy need was also calculated for the entire urban isle (Fig. 4). The largest share of energy consumed in the investigated urban isle is attributed to lighting and equipment (jointly $56 \%$ ), followed by cooling $(33 \%)$ and finally heating $(11 \%)$, in line with the energy demands of the specific case study building previously described.

\subsection{Outdoor area}

The 3D model of the urban Isle was created based on architectural drawings provided by the University of

\section{Energy consumption per energy need}

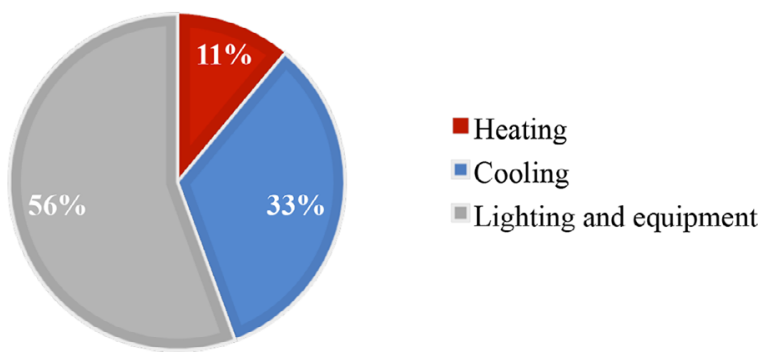

Fig. 4. Limassol building energy consumption breakdown (Design Builder).

Technology, whereas the height of the remaining buildings, the type of vegetation and the outdoor materials were recorded based on onsite observation. The weather data information was collected from a weather station installed by the Cyprus Institute (CyI) SUI project research team, on the roof of the CUT building.

The simulations were performed using the ENVI-met V4.1.2 software, a software used to simulate urban environments and to assess the effects of green architecture on the outdoor thermal comfort. The simulation was run for $6 \mathrm{~h}$, from 10 a.m. to 4 p.m. The hours selected for the simulations are the most compromising in terms of outdoor thermal comfort during summer. Some of the important assumptions made in the ENVI-met simulation process were that the terrain was flat, the buildings' geometry was adjusted to the cubic grid of $1 \mathrm{~m}$, which is the maximum resolution available, and the wind profile had a constant value. 

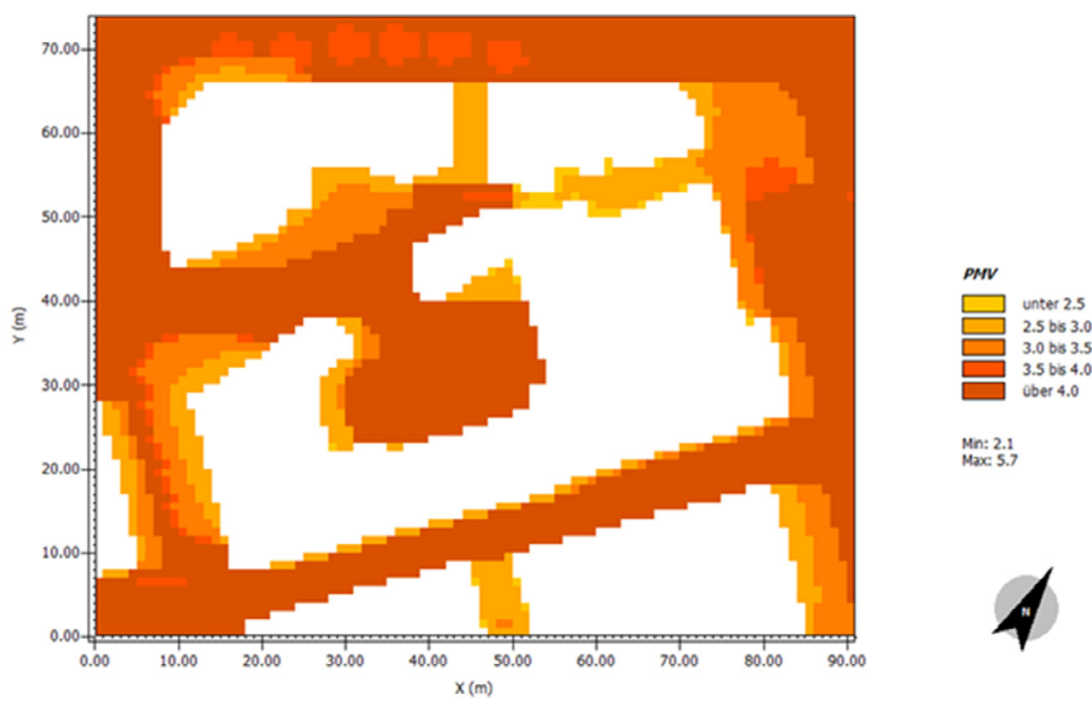

Fig. 5. PMV - Typical summer day at 2 p.m.

Table 3. Limassol energy profile - $\mathrm{CO}_{2}$ emissions (left); Limassol energy profile - energy consumption (right).

\begin{tabular}{|c|}
\hline $\begin{array}{c}\text { SUI Energy Profile_Limassol } \\
\text { CO2 emissions (kgCO2/m2) }\end{array}$ \\
\hline Building \\
\hline 80 \\
\hline Area \\
\hline 142 \\
\hline
\end{tabular}

\begin{tabular}{|c|}
\hline $\begin{array}{c}\text { SUI Energy Profile_Limassol } \\
\text { final energy (kWh/m2) }\end{array}$ \\
\hline Building \\
\hline 116 \\
\hline Area \\
\hline 220 \\
\hline
\end{tabular}

The results from the simulations were processed with ENVI-met application of Biomet for a model of a 35-yearold male, of $80 \mathrm{~kg}$, walking at a speed of $1.2 \mathrm{~m} / \mathrm{s}$. The clothing was set to 0.6 clo for summer, in order to obtain the Predicted Mean Vote (PMV). The PMV is a stationary value, which means that a person is assumed to be exposed long enough to a constant climate situation until all energy exchange processes of the human body have become stationary. This is, of course, only true if this person stands exposed to the same climate conditions for up to $20 \mathrm{~min}$ in some cases [16]. The outcome was visualised with ENVImet application of Leonardo, which produces layered data maps.

From the results it is indicated that during a typical summer day, at the same time range, the PMV does not fall below +2 , ranging from +2.1 to +5.7 , being over +4 (classified as extremely hot) during most of the time and in most of the space. The most compromising time to be outside is between 1-2 pm (Fig. 5).

In summer, mean radiant temperature is the main impact factor for outdoor comfort, with the least uncomfortable spaces being the covered galleries. Nonetheless, even when walking through a covered gallery, the PMV exceeds the accepted value range.

\subsection{The key performance indicators}

As expected, the $\mathrm{CO}_{2}$ emissions and energy consumption accounted for the case study building and the buildings of the surrounding area do not meet the in-force regulation (Directive 432/2013) regarding the minimum energy performance of buildings. For the key performance indicators (Tab. 3), the actual energy consumption data were used. The case study building currently accounts for more than half the $\mathrm{CO}_{2}$ emissions and final energy consumption of the total area.

\section{Building energy retrofitting scenarios and results}

Cyprus has been a member of the EU since 2004 and is therefore bound to comply with the EU legislation. From 2006 onwards, the Republic of Cyprus has been publishing Laws/Directives/Regulations/Rules and National Action Plans concerning the minimum energy requirements to be fulfilled by all new buildings and those falling under the category of "major refurbishment". The legislation follows the Directive 2002/91/EC of the European Commission and after 2010, the Directive 2010/31/EU of the European Parliament on the energy performance of buildings.

The effectiveness of individual measures was explored and a Smart SUI scenario was developed for the case study building. For the energy improvement scenarios and simulations of the Limassol case study building, Design Builder was used to evaluate the energy consumption and performance of the case study building before and after the energy refurbishment measures. 


\section{SUI Scenario}

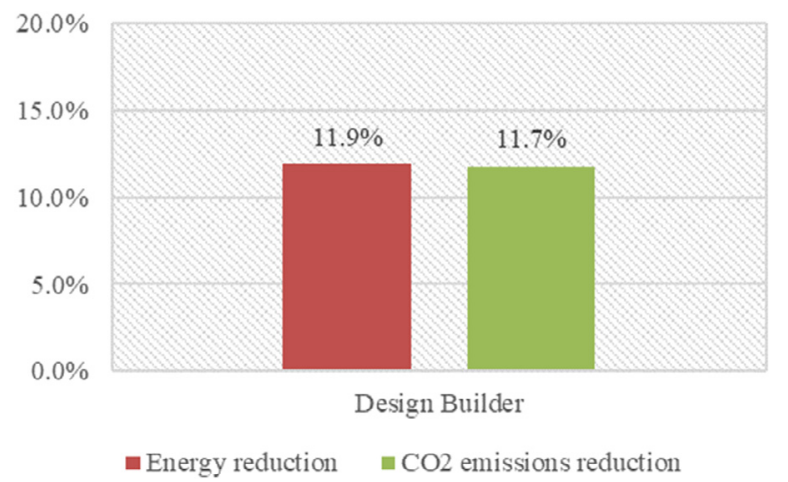

Fig. 6. Limassol building SUI scenario - percentage energy and $\mathrm{CO}_{2}$ reduction (design builder simulation).

In addition, measures towards the improvement of outdoor thermal comfort were investigated. The improvement of outdoor thermal comfort was promoted through these measures, which led to decrease in the energy cooling needs. ENVI-met was used with Biomet, as a postprocessing tool to calculate human thermal comfort indices for the simulation data of ENVI-met, and the results were visualised with Leonardo.

\subsection{Energy retrofitting scenarios}

The minimum energy performance requirements towards an nZEB, as specified by the National Legislation, reduce effectively the heating need $(\approx 90 \%)$, but fail to address as effectively the cooling need $(\approx 50 \%$ reduction $)$, while lighting and equipment are even less affected. The same shortcomings regarding cooling reduction apply for the Label B Scenario refurbishment. The alternative energy retrofitting scenarios were developed taking into consideration the high energy consumption due to cooling and lighting, which are not effectively addressed by the typical nZEB and Label B refurbishments. The energy and cost-effectiveness of the measures below aiming to combat the aforementioned were investigated on an individual basis.

\subsubsection{The optimal building retrofitting scenario}

Based on the reductions achieved by the nZEB scenario and taking into consideration the high energy consumption due to cooling and lighting, which are not effectively addressed by that scenario, the energy and cost-effectiveness of the measures below aiming to combat the aforementioned were investigated on an individual basis.

The energy refurbishment measures below, related to different envelope elements, are used as variables, initially to be examined individually in simulations using the Design Builder. Consequently, the most effective measures are selected to build an optimised scenario, termed "The SUI scenario".

In order to determine which measures to include in the SUI scenario, the measures must also be examined in terms of cost-effectiveness. The most cost-effective measures with

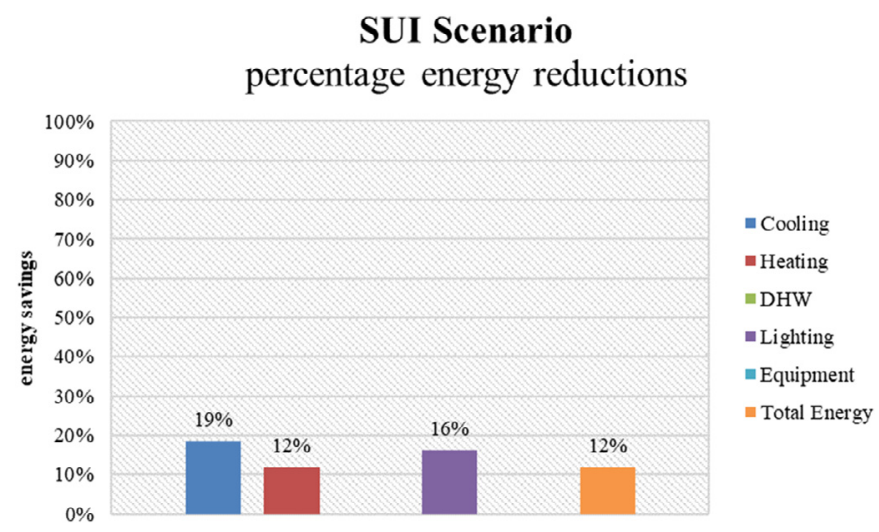

Fig. 7. Limassol building SUI Scenario - percentage energy savings (design builder simulation).

a payback period less than 15 years, in the order of most to least effective, are as follows:

- Add window film shade in the single glazed windows ( 5 years): A window film is added on the external surface of the single glazed windows to intercept the solar heat from entering the building. According to simulations, the total solar transmission value decreases seven-fold when the solar film is applied. The result is $1.6 \%$ reduction in energy needs and $2.6 \%$ reduction in $\mathrm{CO}_{2}$ emissions.

- Substitution of the existing bulbs with LED (10 years): When substituting the existing lighting with LED technology, approximately $76 \%$ lower normalised power density (irradiance) is simulated. This results in $4.4 \%$ reduction in energy demand and $5.3 \%$ reduction in $\mathrm{CO}_{2}$ emissions.

- Control the indoor temperature (12 years): The comfort temperature range is increased from $22-26$ to $19-27^{\circ} \mathrm{C}$, decreasing the heating set point by $3^{\circ}$ and increasing the cooling set point by $1^{\circ}$ [7]. The temperatures are controlled using a programmable thermostat, and this measure results in $4.7 \%$ reduction in energy needs and $2.6 \%$ reduction in $\mathrm{CO}_{2}$ emissions.

- Cool paint for the roof (15 years): Painting the roof with a cool paint prevents the building from overheating and results in almost $1 \%$ reduction in energy consumption and $\mathrm{CO}_{2}$ emissions.

The above measures were combined in order to build the SUI scenario. The results of the simulations of this scenario are presented in Figure 6.

The energy consumption of the case study building is reduced by approximately $12 \%$ according to the SUI scenario, similar to the cutbacks in $\mathrm{CO}_{2}$ emissions. As for the individual energy services of the building (Fig. 7), the highest percentage of energy savings occurs from cooling (19\%), followed by lighting (16\%) and then heating (12\%). There is no RES contribution in this scenario and the payback period is estimated to be 10 years.

\subsubsection{Proposed surrounding area retrofitting scenario}

A scenario for the enhancement of the outdoor comfort was developed, using replacement of asphalt and pavement with granite single stones and doubling the number of trees 

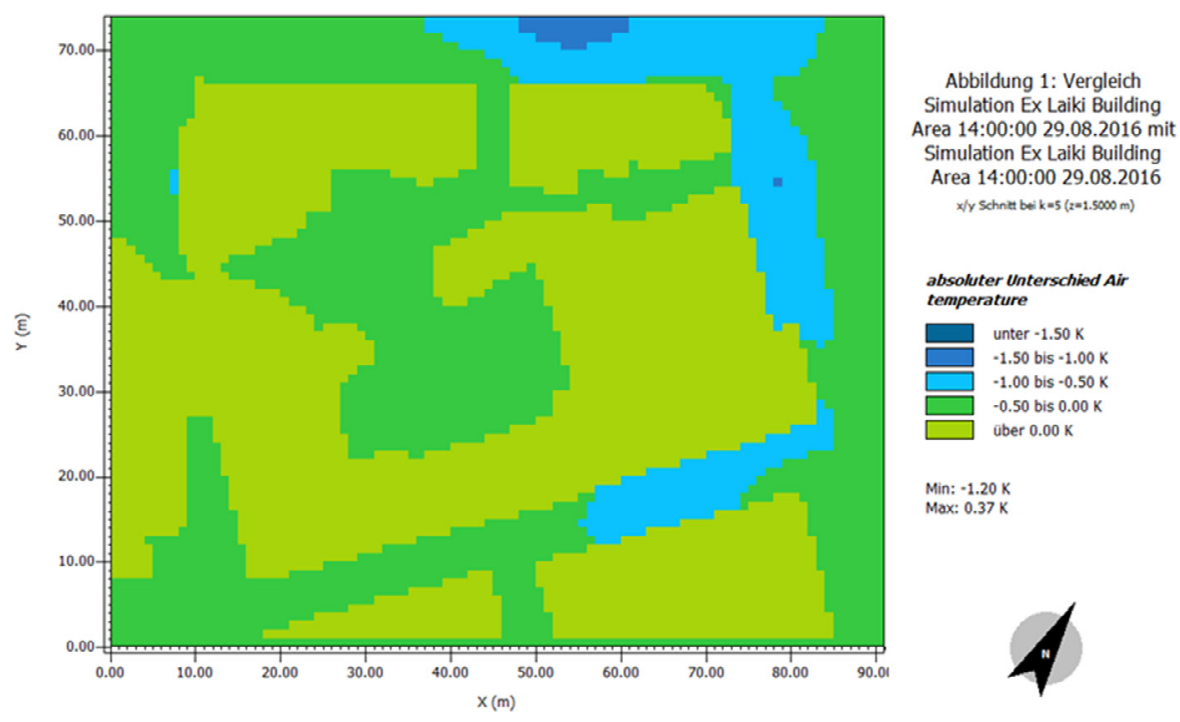

Fig. 8. Absolute difference in temperature in summer at 2 p.m. - comparison before and after the measures.

in the urban isle (Fig. 8). The results indicate $0.8 \mathrm{~K}$ reduction in air temperature on average, and expected decrease in cooling demand by $1.5-2.0 \%$ [17].

\subsection{Bioclimatic scenarios combined impact}

The SUI refurbishment of the public building can lead to approximately $28 \mathrm{MWh}$ yearly reductions in its energy consumption. With the outdoor area retrofitted, a reduction of $2 \%$ is expected on the cooling demand of all the SUI buildings. This will further decrease the energy consumption of the isle buildings by $5.83 \mathrm{MWh}$ per year. The subsequent total reduction in $\mathrm{CO}_{2}$ emissions will be up to almost 24 tons $\mathrm{CO}_{2} /$ year, which corresponds to an overall percentage decrease of $4 \%$.

\section{Conclusion}

The current case study of the urban isle with the buildings have indicated that major energy consumption patterns are observed in the cooling, lighting and equipment services of the constructions in Cyprus. Therefore, energy refurbishments in Cyprus must focus primarily on minimising the cooling needs of the buildings. The results of the study show that addressing these energy draining issues by following the directives for the nZEB and Label $\mathrm{B}$ certification as guidelines is not cost-effective. Furthermore, the results demonstrate that the buildings can reduce their energy consumption by means of easily applicable, bioclimatic, cost-effective measures. Improving the energy efficiency of the buildings in combination with the outdoor materiality induces higher, more generalised and permanent reductions in energy consumption and $\mathrm{CO}_{2}$ emissions. Specifically, through the analysis of the various developed scenarios and simulations, it has transpired that individual bioclimatic measures such as applying window film shade, conversion to LED lighting, controlling the indoor temperatures with automated thermostats and applying cool paint on the roof can result in energy consumption and $\mathrm{CO}_{2}$ emission reductions of more than $10 \%$, in this Mediterranean setting. A prospect for future studies in this field is the development of an integrated approach with a model that simulates the effects of bioclimatic building modifications on the outdoor environment and pedestrian thermal comfort. Conversely, another possible pathway would be to investigate the impact of outdoor thermal comfort on indoor thermal conditions and patterns of energy consumption. Future studies can therefore explore the dynamic relationship between indoor and outdoor thermal comfort, the effect on the energy consumption and the consequent bearing on urban sustainability.

The authors would like to thank the EU and the Research Promotion Foundation for funding, in the frame of the collaborative international Consortium (SUI) financed under the ERA-NET Cofund SmartCities and Communities Cofunded Call. This ERA-NET is an integral part of the 2014 Joint Activities developed by the Joint Programme Initiative Urban Europe (JPI Urban Europe).

\section{References}

1. UN, World Urbanization Prospects: The 2018 Revision, 2018

2. A. Grubler, X. Bai, T. Buettner, S. Dhakal, D.J. Fisk, T. Ichinose et al., Urban energy systems, in Global Energy Assessment - Toward a Sustainable Future, edited by T.B. Johansson et al. (Cambridge University Press, Cambridge, 2012)

3. K. Friedman, A. Cooke, City versus national energy use: implications for urban energy policy and strategies, Procedia Eng. 21, 464 (2011)

4. UNEP, Global Initiative for Resource Efficient Cities: Engine to Sustainability, 4, 2012. Available at https://europa.eu/ capacity4dev/unep/document/global-initiative-resourceefficient-cities-brief 
5. D. Serghides, Open Constr. Build. Technol. J. 4, 29 (2010)

6. V.A. Metallinou, Ecological propriety and architecture, in WIT Transactions on the Built Environment (2006), pp. 15-22. doi:10.2495/ARC060021

7. D. Serghides, S. Dimitriou, I. Kyprianou, C. Papanicolas, The adaptive comfort factor in evaluating the energy performance of office buildings in the Mediterranean coastal cities, Energy Procedia 134, 683 (2017)

8. M. Santamouris, Innovating to zero the building sector in Europe: minimising the energy consumption, eradication of the energy poverty and mitigating the local climate change, Sol. Energy 128, 61 (2016)

9. A. Chatzidimitriou, S. Yannas, Microclimate design for open spaces: ranking urban design effects on pedestrian thermal comfort in summer, Sustain. Cities Soc. 26, 27 (2016)

10. I. Karakounos, A. Dimoudi, S. Zoras, The influence of bioclimatic urban redevelopment on outdoor thermal comfort, Energy Build. 158, 1266 (2018)

11. C. Chatzinikola, D.K. Serghides, M. Santamouris, Effect of the orientation on the winter indoor temperatures and on the energy consumption of low-income dwellings in the Mediterranean region, in International Conference with
Exhibition S. ARCH-Environment and Architecture, Montenegro, 2015, pp. 1-9

12. D.K. Serghides, S. Dimitriou, M.C. Katafygiotou, M. Michaelidou, Energy efficient refurbishment towards nearly zero energy houses, for the Mediterranean region, Energy Procedia 83, 533 (2015)

13. D.K. Serghides, M. Michaelidou, M. Christofi, S. Dimitriou, M. Katafygiotou, Energy refurbishment towards nearly zero energy multi-family houses for Cyprus, Procedia Environ. Sci. 38, 11 (2017)

14. Urban Europe, Smart Urban Isle. Available at https:// jpi-urbaneurope.eu/project/smart-urban-isle/ (accessed 23 May 2018)

15. MECIT, 4th National Action Plan for Energy Efficiency of Cyprus (in Greek), Nicosia, 2017. Available at http://www. mcit.gov.cy/mcit/EnergySe.nsf / All/EF97759A9580E25EC 22581C500345706/\$file/4oE $\Sigma \Delta$ EA_19_09_17.pdf

16. ENVI-met website. PMV and PPD. Available at http:// www.envi-met.com/documents / onlinehelpv3/hs550.htm (accessed 2 March 2017)

17. H. Akbari, M. Pomerantz, H. Taha, Cool surfaces and shade trees to reduce energy use and improve air quality in urban areas, Sol. Energy 70, 295 (2001)

Cite this article as: D.K. Serghides, S. Dimitriou, I. Kyprianou, C. Papanicolas, The bioclimatic approach in developing smart urban isles for sustainable cities, Renew. Energy Environ. Sustain. 4, 2 (2019) 